\title{
Gender dependent accumulation of dioxins in smokers
}

\author{
S Fierens, G Eppe, E De Pauw, A Bernard
}

Occup Environ Med 2005;62:61-62. doi: 10.1136/oem.2004.013730

\begin{abstract}
Aims: To evaluate the contribution of tobacco smoking to dioxin accumulation.

Methods: Dioxin (17 PCDD/F) concentrations in fasting blood from 251 subjects (161 never smokers, 54 past smokers, and 36 current smokers) were quantified.

Results: Whereas serum dioxin concentrations of male smokers were on average $40 \%$ higher than those of nonsmokers, in women, smoking was associated with significantly lower serum dioxin levels. A synergistic potentiation of dioxin metabolism by tobacco smoke in women is postulated to explain these paradoxical findings.

Conclusions: Current smoking is associated with gender dependent effects on dioxin body burden and is a potential source of confounding in human studies using blood dioxins as indicators of exposure.
\end{abstract}

$\mathrm{T}$ bacco smoke contains a variety of polycyclic hydrocarbons, including dioxins (polychlorinated dibenzodioxins/dibenzofurans). It has been estimated that smoking 20 cigarettes per day should lead to a dioxin intake almost equivalent to that from food ( $1-3 \mathrm{pg} T E Q / \mathrm{kg}$ bw/day), the major source of human exposure. ${ }^{1-3}$ However, studies that have measured dioxins in smokers did not find higher levels; some studies on breast milk even reported significantly lower values than in non-smokers. ${ }^{45}$ We show here that dioxin concentrations are affected by a gender-smoking interaction that could exert a confounding effect.

\section{METHODS}

Volunteers were recruited during a study conducted in order to estimate the environmental exposure to dioxins in different areas of Wallonia, Belgium. A total of 251 nonoccupationally exposed participants, aged $21-80$ years, were examined, including 36 current smokers, 54 past smokers ( 13 years on average since smoking cessation), and 161 never smokers. The proportions of subjects living within $2 \mathrm{~km}$ of an incinerator, the only environmental source found to affect dioxin body burden in this study, ${ }^{6}$ were not significantly different between the three smoking categories $(33 \%, 37 \%$, and $30 \%$ respectively; $\chi^{2}=0.82 ; p=0.66$ ). Information about smoking habits, dietary habits, anthropometric characteristics, residential history, and health status was obtained from

\section{Main messages}

- Male smokers have higher serum dioxin levels than non-smokers, whereas female smokers have lower serum dioxin levels than non-smokers.

- Current smoking is a potential source of confounding in human studies using blood dioxins as indicator of exposure. a self-administered questionnaire. The volunteers provided approximately $200 \mathrm{ml}$ of blood under fasting conditions in order to evaluate the body burden of dioxins. The seventeen 2,3,7,8-substituted polychlorinated dibenzodioxin/dibenzofuran (PCDD/Fs) and four "dioxin-like" coplanar polychlorinated biphenyls (cPCBs no. 77, 81, 126, 169) congeners were quantified by gas chromatography-high resolution mass spectrometry (GC-HRMS) on the lipid fraction of serum. ${ }^{7}$ The results were reported per gram fat and expressed in toxic equivalents (TEQ)

\section{RESULTS}

When data from both sexes were combined, serum dioxin concentrations appeared virtually identical between current smokers, past smokers, and never smokers (geometric mean: 25.6, 25.6, and $25.7 \mathrm{pg}$ TEQ/g fat, respectively; ANOVA: $\mathrm{F}=0$; $\mathrm{p}=1$ ). The analysis by gender, however, revealed that dioxin levels were significantly higher in male current smokers but lower in female current smokers (table 1). The same pattern of effects was observed with coplanar PCBs. Current smokers did not present any difference in age, body mass index (BMI), or animal fat intake, compared with never smokers, that could explain these discrepant variations, the decrease of dioxin levels observed in female smokers being on average associated with a higher animal fat intake. A stepwise multiple linear regression analysis testing possible predictors (smoking status, age, BMI, animal fat intake, residence around incinerator, fish or alcohol consumption, menopause, contraceptive pills, lactation) confirmed the increase of serum dioxin levels in male current smokers (partial $r^{2}=0.038$, slope $\left.=0.14, p=0.013\right)$ and the decrease in female current smokers $\left(r^{2}=0.043, \quad\right.$ slope $=-0.14$, $\mathrm{p}=0.006$ ). As illustrated in fig $\mathrm{l}$, serum dioxin levels adjusted for age and other covariates were on average $39.4 \%$ higher in male current smokers and $27.5 \%$ lower in female current smokers than in the respective control groups of never smokers. A two way ANOVA on adjusted dioxin values showed a highly significant interaction between gender and smoking status (current smokers or not) (model: $\mathrm{F}=5.81, \mathrm{p}=0.0008$; interaction: $\mathrm{F}=17.09, \mathrm{p}<0.0001)$.

\section{DISCUSSION}

The increase in dioxin body burden observed in male current smokers is in accordance with their higher intake of dioxins as predicted from their smoking habits. ${ }^{3}$ That past smokers of both sexes present normal levels is not really surprising since they have stopped smoking on average 13 years ago, a time

\section{Policy implications}

- When measuring blood dioxins as indicator of exposure in populations including current smokers, data from male and female smokers should be analysed separately. 
Table 1 Characteristics and dioxin concentrations of men and women according to their smoking status

\begin{tabular}{|c|c|c|c|c|c|c|}
\hline & \multicolumn{6}{|l|}{ Smoking status } \\
\hline & \multicolumn{3}{|l|}{ Men } & \multicolumn{3}{|l|}{ Women } \\
\hline & Never & Past & Current & Never & Past & Current \\
\hline Number & 56 & 37 & 19 & 105 & 17 & 17 \\
\hline Age (years) & $51.9(9.5)$ & $52.9(9.9)$ & $53.3(7.5)$ & $51.9(10.3)$ & $47.7(8.09)$ & $50.1(10.7)$ \\
\hline $\mathrm{BMI}\left(\mathrm{kg} / \mathrm{m}^{2}\right)$ & $25.4(24.5$ to 26.5$)$ & $27.3(26.4 \text { to } 28.4)^{*}$ & 26.3 (24.9 to 27.9 ) & 25.3 (24.4 to 26.2 ) & 26.2 (24.2 to 28.7$)$ & $24.3(22.5$ to 26.4$)$ \\
\hline Fat intake (g/wk) & 293 (255 to 337$)$ & $272(230$ to 322$)$ & $273(208$ to 360$)$ & 241 (221 to 263 ) & $282(232$ to 344$)$ & $324(266 \text { to } 394)^{*}$ \\
\hline Pack-years & - & $20.4(15.3$ to 27.1$)$ & $18.8(11.6$ to 30.5$)$ & - & $9.4(5.9$ to 15.1$)$ & 13.1 (7.5 to 22.8$)$ \\
\hline Cigarettes/day & - & 22.6 (19.7 to 25.9 ) & $11.3(7.2 \text { to } 17.7)^{*}$ & - & 13.8 (10.3 to 18.5$)$ & 10.5 (7.5 to 14.8$)$ \\
\hline \multicolumn{7}{|c|}{ Dioxin and cPCBs concentrations (pg TEQ/g fat) } \\
\hline PCDDs & $11.9(10.0$ to 14.0$)$ & $12.7(10.1$ to 16.0$)$ & $17.7(14.1 \text { to } 22.2)^{*}$ & 13.9 (12.6 to 15.5$)$ & $13.3(10.8$ to 16.3$)$ & $9.3(6.2 \text { to } 14.1)^{*}$ \\
\hline PCDFs & $11.4(9.9$ to 13.3$)$ & $12.7(10.8$ to 14.9$)$ & $15.4(12.4$ to 19.2$)$ & $12.8(11.6$ to 14.1$)$ & $11.4(8.9$ to 14.6$)$ & $9.4(7.2 \text { to } 12.3)^{*}$ \\
\hline Total PCDD/Fs & $23.5(20.2$ to 27.4$)$ & $25.9(21.8$ to 30.9$)$ & $33.4(26.9 \text { to } 41.4)^{*}$ & $27.0(24.5$ to 29.7$)$ & 24.8 (19.9 to 31.0$)$ & $19.1(13.8 \text { to } 26.3)^{*}$ \\
\hline Coplanar PCBs & $7.2(6.2$ to 8.4$)$ & $7.6(6.2$ to 9.2$)$ & $8.7(6.4$ to 12.0$)$ & $7.8(7.0$ to 8.8$)$ & $6.5(4.7$ to 9.0$)$ & $5.1(3.5 \text { to } 7.4)^{*}$ \\
\hline
\end{tabular}

Data are geometric mean ( $95 \% \mathrm{Cl}$ ) except age (arithmetic mean (SD)) and BMI (harmonic mean (95\% CI)). Fat intake was calculated from the consumption of poultry, bovine, and swine products.

${ }^{*} \mathrm{p}<0.05$ for differences with never smokers (past smokers in case of tobacco consumption), by gender.

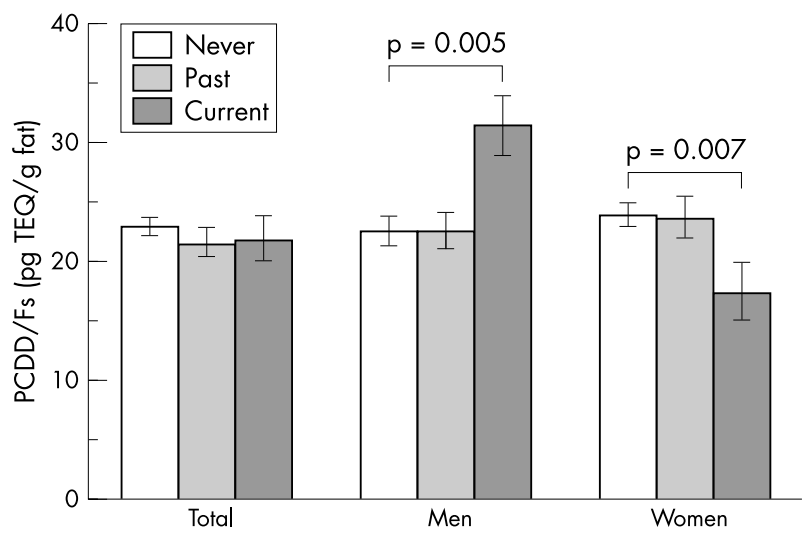

Figure 1 Dioxin concentrations in serum according to gender and smoking status. Dioxin values are adjusted for age, BMI, fat intake, and residence around incinerators in men; and in women for age and residence around incinerators. See table 1 for numbers of subjects in each category.

sufficient for their dioxin body burden to re-equilibrate with that of never smokers. By contrast, the significant decrease of dioxin levels in female current smokers as opposed to the increase in male smokers is a quite unexpected finding. The most plausible explanation is a strong stimulation of dioxin biotransformation by polycyclic aromatic hydrocarbons (PAHs) or other chemicals contained in tobacco smoke. Indeed, tobacco smoke contains compounds with affinity for the Ah receptor, that could then be potent inducers of cytochrome P450 enzymes. ${ }^{8} 9$ The reason why this induction, which proceeds through the Ah receptor, would manifest mainly in women is still unclear. A possible mechanism could involve the recently demonstrated cross-talk between the Ah receptor and oestrogen mediated signalling pathways, a cooperation between receptors that could lead in women to a synergistic potentiation of dioxin metabolism by chemical compounds of tobacco smoke. ${ }^{10}$ Independently of its mechanism, this gender dependent effect of current smoking is a potential source of confounding in human studies using blood dioxins as indicator of exposure.

\section{ACKNOWLEDGEMENTS}

We thank the volunteers who provided us with blood samples. This work was supported by the Ministry of Environment of the Walloon Region and by the European Union. S Fierens is Research Fellow of the Brussels-Capital Region and A Bernard is Research Director of the National Fund for Scientific Research, Belgium.

\section{Authors' affiliations}

S Fierens, A Bernard, Unit of Toxicology and Occupational Medicine, School of Public Health, Université catholique de Louvain, 30.54 ClosChapelle-aux-Champs, B-1200 Brussels, Belgium

G Eppe, E De Pauw, Mass Spectrometry Laboratory, University of Liège, Allée de la Chimie 3-B6c, Sart-Tilman B-4000 Liège, Belgium

Correspondence to: Professor A Bernard, Unit of Toxicology and Occupational Medicine, School of Public Health, Université catholique de Louvain, 30.54 Clos-Chapelle-aux-Champs, B-1200 Brussels, Belgium; Bernard@toxi.ucl.ac.be

Accepted 8 July 2004

\section{REFERENCES}

1 Aoyama T, Ikeda K, Takatori A, et al. Risk assessment of dioxins in cigarette smoke. Organohalogen Compd 2003;65:321-4.

2 Birnbaum L, Farland $W$. Health risk characterization of dioxins and related compounds. In: Schecter A, Gasiewicz TA, eds. Dioxins and health. Hoboken: John Wiley \& Sons, 2004:159-90.

3 Muto H, Takizawa Y. Dioxins in cigarette-smoke. Arch Environ Health 1989;44:171-4.

4 Cuijpers C, Liem AK, Albers M. Determinants influencing levels of polychlorinated organic compounds in human milk. Organohalogen Compd 1996;30:43-8.

5 Furst $P$, Furst $C$, Wilmers K. PCDDs and PCDFs in human milk-statistical evaluation of a 6-years survey. Chemosphere 1992;25:1029-38.

6 Fierens S, Mairesse $\mathrm{H}$, Hermans, et al. Dioxin accumulation in residents around incinerators. J Toxicol Environ Health Part A 2003;66:1287-93.

7 Focant JF, De Pauw E. Fast automated extraction and clean-up of biological fluids for polychlorinated dibenzo-p-dioxins, dibenzofurans and coplanar polychlorinated biphenyls analysis. Journal of Chromatography B Analytical Technologies in the Biomedical and Life Sciences 2002;776:199-212.

8 Bao HF, Vepakomma M, Sarkar MA. Benzo(a)pyrene exposure induces CYP1A1 activity and expression in human endometrial cells. J Steroid Biochem Mol Biol 2002;81:37-45.

9 Lofroth G, Rannug A. Ah receptor ligands in tobacco smoke. Toxicol Lett 1988;42:131-6.

10 Ohtake F, Takeyama K, Matsumoto T, et al. Modulation of oestrogen receptor signalling by association with the activated dioxin receptor. Nature
$2003 ; 423: 545-50$. 